Revista Brasileira de Agricultura Irrigada v.9, nº.5, p. 292 - 299, 2015

ISSN 1982-7679 (On-line)

Fortaleza, CE, INOVAGRI - http://www.inovagri.org.br

DOI: $10.7127 /$ rbai.v9n500308

Protocolo 308.15 - 25/05/2015 Aprovado em 10/09/2015

\title{
CONSTRUÇÃO, INSTALAÇÃO E CALIBRAÇÃO DE LISÍMETRO DE LENÇOL FREÁTICO DE CARGA CONSTANTE NA REGIÃO SEMIÁRIDA DE PERNAMBUCO
}

\author{
Célia Silva dos Santos ${ }^{1}$, Abelardo Antônio de Assunção Montenegro ${ }^{2}$, Renato Augusto Soares \\ Rodrigues $^{3}$, Daniella Pereira dos Santos ${ }^{4}$, Adriano Luiz Normandia Monteiro ${ }^{5}$
}

\begin{abstract}
RESUMO
O método direto mais comum utilizado na estimativa da evapotranspiração de uma cultura é o método lisimétrico. Assim, o objetivo deste trabalho foi construir, instalar, calibrar um lisímetro de lençol freático de carga constante, correlacionando a evapotranspiração de referência (ETo) àquela obtida a partir de modelo agrometeorológico de Penman-Monteith FAO-56, no semiárido Pernambucano. O lisímetro de lençol freático instalado na área experimental possui dimensões 0,80 x 1,36 m, representando uma área $1,45 \mathrm{~m}^{2}$, um tanque intermediário e um tanque medidor de nível freático interligados. Após a escavação da trincheira no solo e colocação do lisímetro, procedeu-se ao preenchimento com uma camada de brita, manta poliéster e as camadas de solo na ordem inversa da sua retirada, mantendo a disposição original das mesmas no perfil. Após o preenchimento do lisímetro com solo, foi realizada a calibração do mesmo por meio de análise de regressão linear, e toda a área foi plantada com grama. O lisímetro foi instalado e calibrado adequadamente, apresentando boas condições de funcionamento e permitindo a obtenção de medidas de evapotranspiração em concordância com estimativas realizadas pelo método de Penman-Monteith, na região de Mutuca - PE.
\end{abstract}

Palavras-chave: evapotranspiração de referência, lisimetria, manejo da irrigação.

\section{CONSTRUCTION, INSTALLATION AND CALIBRATION LOAD OF WATER TABLE LYSIMETER CONSTANT IN THE REGION OF PERNAMBUCO SEMIARID}

\begin{abstract}
This study aimed to construct, install, calibrate a lysimeter with a static water table, correlating the reference evapotranspiration (ETo) that obtained from agro-meteorological model PenmanMonteith FAO-56, in the semiarid of Pernambuco. Groundwater lysimeter installed in the

\footnotetext{
${ }^{1}$ Doutoranda em Engenharia Agrícola, UFRPE, 52171-900, Recife-PE, celia_agron@hotmail.com

${ }^{2}$ Professor Titular, UFRPE, 52171-900, Recife-PE,abelardo.montenegro@yahoo.com.br

${ }^{3}$ Mestrando em Engenharia Agrícola, UFRPE, 52171-900, Recife-PE, renato.augustor@hotmil.com

${ }^{4}$ Doutoranda em Engenharia Agrícola, UFRPE, 52171-900, Recife-PE, daniella.psantos@hotmail.com

${ }^{5}$ Doutor em Engenharia Agrícola, UFRPE, 52171-900, Recife-PE, ad_normandia@hotmail.com
} 
experimental area has dimensions 0,80 x 1,36 m, representing a 1,45 $\mathrm{m}^{2}$ area, an intermediate tank and a water table meter tank interconnected. After the trench digging in the soil and placing the lysimeter, it proceeded to fill with gravel layer, polyester blanket and soil layers in reverse order of their removal, maintaining the original layout of the same profile. After filling the lysimeter with soil, its calibration was performed by linear regression analysis, and the entire area was planted with grass. The built lysimeter was installed and calibrated properly, with good working order and capable of producing evapotranspiration measures in line with estimates made by the PenmanMonteith method, in the region of Mutuca - PE.

Keywords: reference evapotranspiration, lysimeters, irrigation management.

\section{INTRODUÇÃO}

Segundo Faria et al. (2006) a quantificação do fluxo de vapor d'água para a atmosfera proveniente de superfícies úmidas, como áreas cultivadas ou em pousio, é de grande interesse para determinação das necessidades hídricas de cultivos e disponibilidade hídrica do solo.

Como a água constitui um dos principais insumos destinados à produção de alimentos, a evapotranspiração de referência (ETo) assume aspecto fundamental no planejamento agrícola, pois é largamente utilizada na estimativa da demanda de água pela planta (Kashyap e Panda, 2001).

Santos et al. (2008), afirmam que a evapotranspiração é um processo natural de perda de água do solo e da planta para a atmosfera, constituindo-se em parâmetro de grande relevância para o manejo agrícola, particularmente em regiões onde predominam elevados déficits hídricos anuais, como, por exemplo, o semiárido nordestino. Nessas áreas, a irrigação, aliada à aquisição de dados confiáveis de evapotranspiração, torna-se essencial.

Lisímetros de pequena capacidade podem ser usados na medição da evapotranspiração em plantas de pequeno porte. São indicados também para culturas de grande porte no início do ciclo de desenvolvimento, isso em decorrência de sua menor resolução, podendo ser usados tanto em viveiros de mudas, quanto no campo, nas etapas iniciais de desenvolvimento, Velame et al. ( 2012).
Segundo Machado e Mattos (2001) recentemente têm sido bastante utilizados lisímetros com lençol freático constante, devido a sua boa precisão e a facilidade em variar a profundidade do lençol no seu interior. Este tipo de equipamento encontra-se bastante difundido no Brasil. Moura et al. (1994) utilizaram lisímetros com lençol freático constante em seus experimentos para a determinação do consumo de água pelas culturas, e constataram a facilidade de operação e boa precisão. A dificuldade em se automatizar as leituras é uma desvantagem desse tipo de lisímetro.

Tendo em vista a inexistência de medidas de evapotranspiração de referência e a importância desse parâmetro no planejamento e no manejo da agricultura irrigada, desenvolveu-se este trabalho com o objetivo de construir, instalar, calibrar um lisímetro de lençol freático de carga constante correlacionando-a evapotranspiração determinada e estimada por modelo agrometeorológico Penman-Monteith FAO56, no semiárido Pernambucano.

\section{MATERIAL E MÉTODOS}

\section{Caracterização da área experimental}

$\mathrm{O}$ estudo foi realizado no distrito de Mutuca, município de Pesqueira, PE, na Unidade Piloto de Tratamento e Reuso de Esgoto Doméstico (ETE). Essa região possui o clima semiárido quente, e apresenta temperatura média de $27^{\circ} \mathrm{C}$, umidade relativa do ar de $73 \%$ e precipitação média anual de 670 mm (Molinier et al. 1994). 


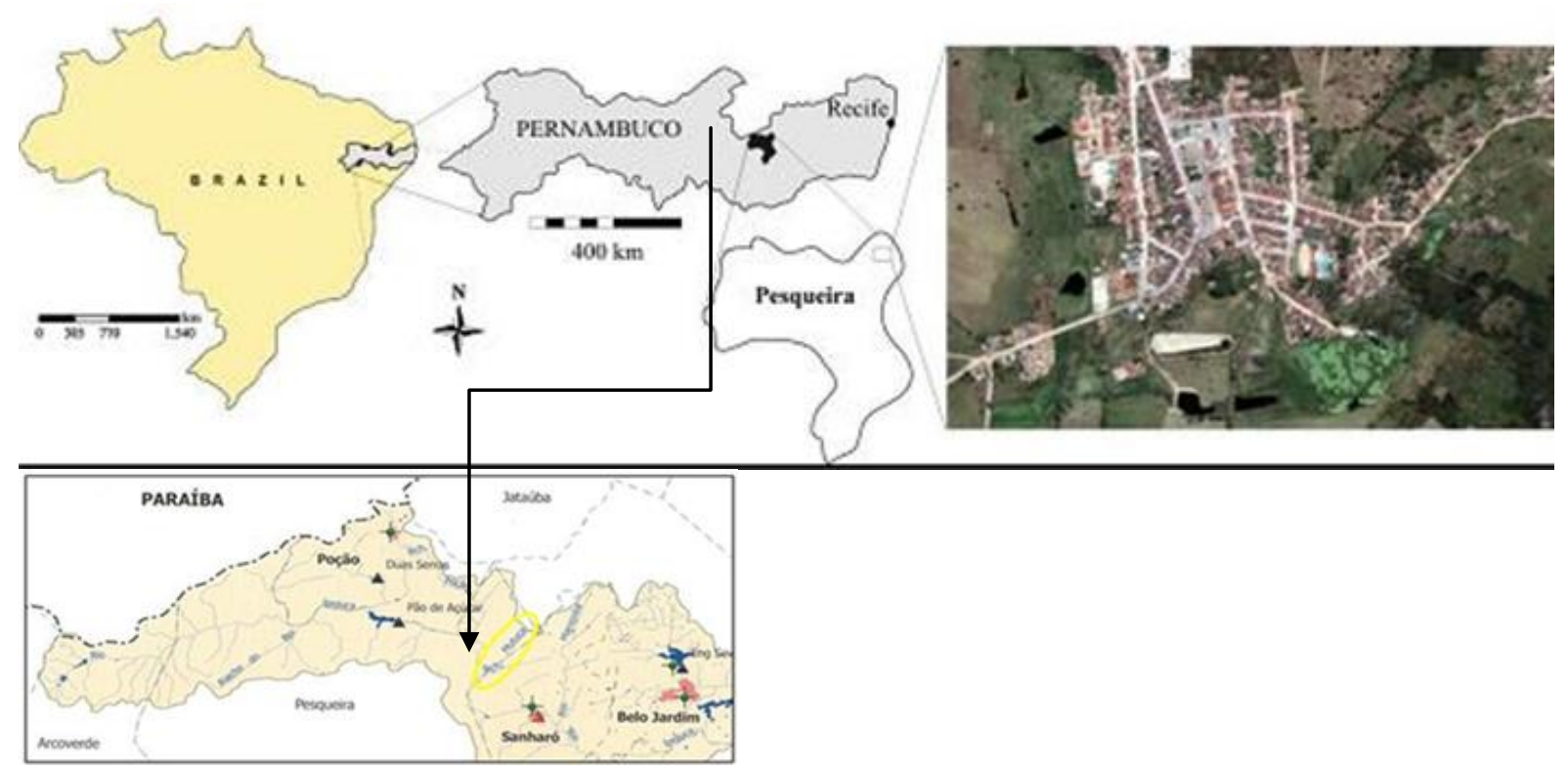

Figura 1. Localização da Comunidade de Mutuca-PE.

\section{Construção e instalação dos lisímetros}

O consumo de água pela grama foi medido através do lisímetro de lençol freático com carga constante. O lisímetro foi composto de uma caixa de polietileno (A), tanque intermediário (B) e tanque medidor (C) como mostra a Figura 2. A bateria lisimétrica corresponde à caixa de 1.000 litros, com diâmetro de 1,36 m e profundidade de $80 \mathrm{~cm}$, ou seja, com uma área de exposição de aproximadamente 1,45 $\mathrm{m}^{2}$, a altura do lençol freático em cada tanque foi de $50 \mathrm{~cm}$ a partir da superfície do solo.
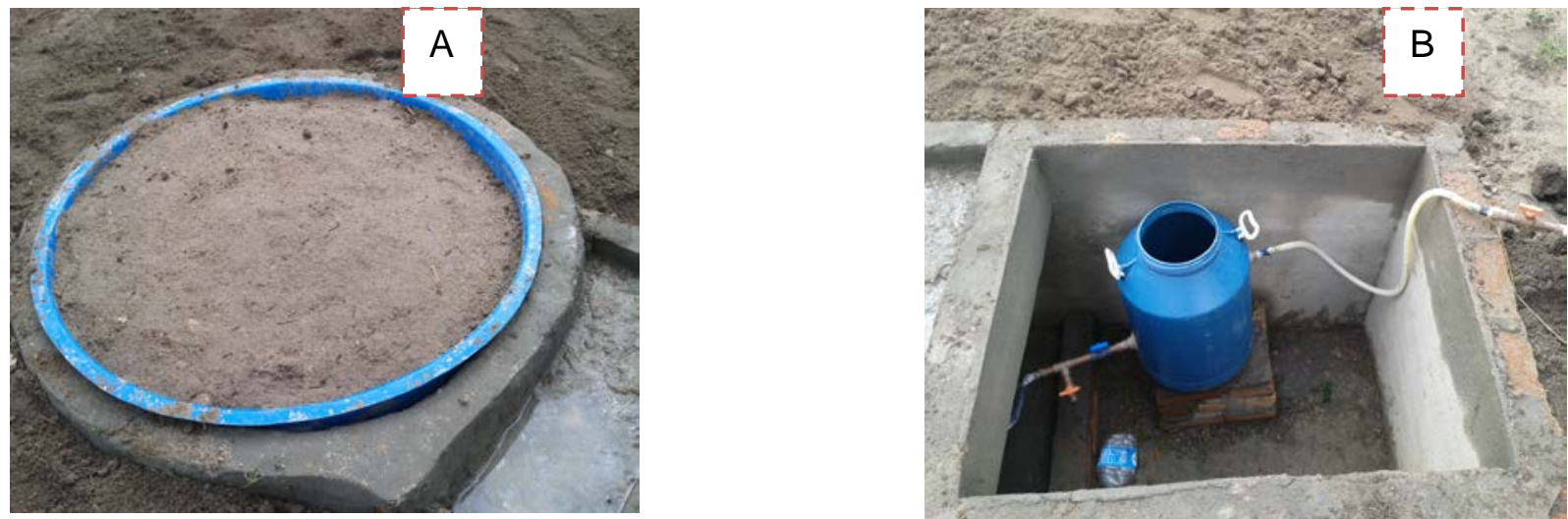
Santos et al.
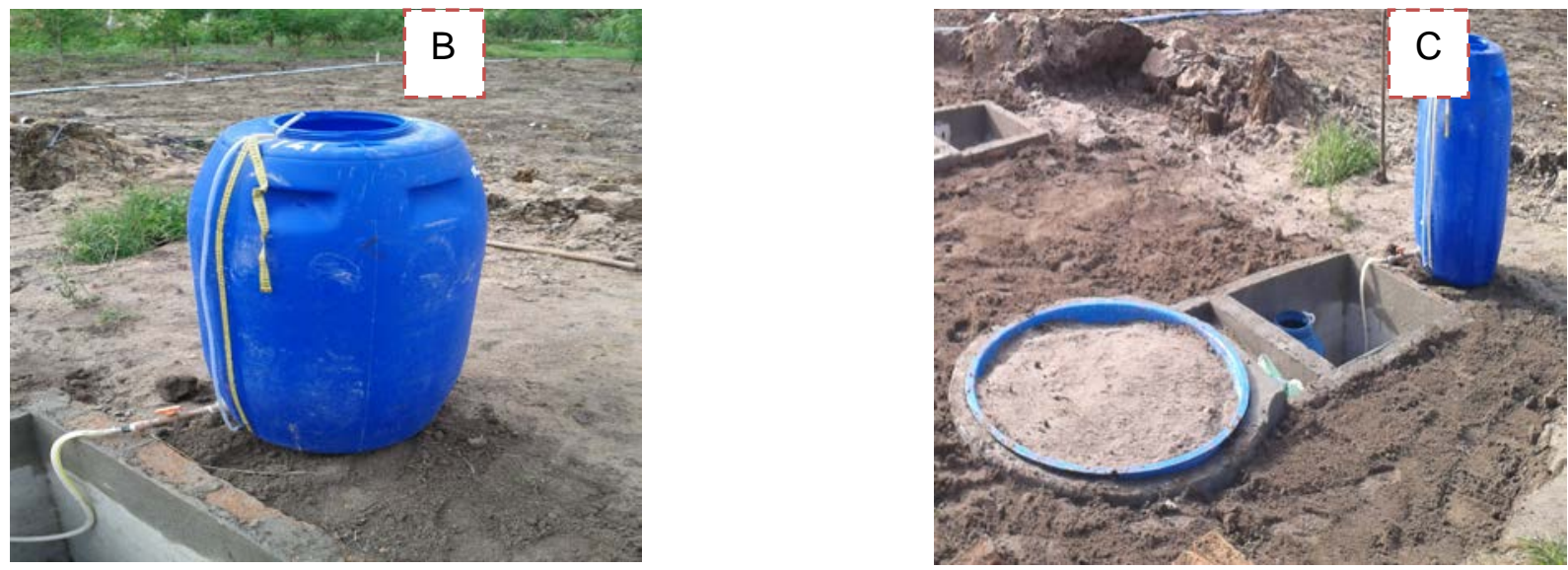

Figura 2. Lisímetro de lençol freático de carga constante, caixa de polietileno (A), tanque intermediário (B) e tanque medidor (C) instalado em Mutuca- PE.

Para a instalação de cada lisímetro de drenagem foram feitas escavações manualmente das trincheiras tomando-se o cuidado de separar o solo em quatro camadas de $0,20 \mathrm{~m}$. As quatro camadas de $0,20 \mathrm{~m}$ de solo foram identificadas $(0-0,20 \mathrm{~m} ; 0,20$ $0,40 \mathrm{~m} ; \quad 0,40-0,60 \mathrm{~m}$ e $0,60-0,80 \mathrm{~m})$ e armazenadas no próprio local.

É importante salientar que a metodologia utilizada na escavação, separação e acondicionamento do solo permite a reconstituição das condições iniciais do solo. Sendo assim os lisímetros foram introduzidos, nivelados e antes de serem novamente preenchidos com o solo da área na forma inversa para manter as condições originais, foram colocadas $10 \mathrm{~cm}$ de camada de brita na parte inferior do lisímetro. Em seguida, os lisímetros foram preenchidos, obedecendo aos perfis originais do solo no local.

Calibração do lisímetro de lençol freático de carga constante

Para efetuar a calibração do lisímetro de lençol freático de carga constante foi estabelecido o nível do lençol de $50 \mathrm{~cm}$ em relação à superfície do solo e provocado a retirada de 1,36 L de água do tanque medidor e posteriormente avaliado o abaixamento do nível do lençol freático, valor esse que corresponde ao diâmetro exposto do lisímetro. Inicialmente foi determinada a relação, por meio de regressão linear, entre o volume retirado e o abaixamento do lençol medido. A relação entre a grandeza de entrada de um sistema de medição e a sua resposta (saída) pode ser expresso por meio de uma equação de regressão linear.

A fim de avaliar o funcionamento do lisímetro, medidas de ETo foram efetuadas e comparadas com estimativas realizadas pelo método de Penman-Monteith FAO 56 (Allen et al. 1998), cujos dados climáticos necessários foram coletados em estação automática montada a 10 metros do lisímetro. A estação continha os sensores de radiação solar incidente, velocidade e direção do vento, temperatura, pressão atmosférica e precipitação, além de um pluviógrafo.

Determinação da evapotranspiração de referência (ETo) padrão-grama

A grama cultivada em lisímetro retirava do solo por capilaridade a quantidade de água para atender a demanda atmosférica. Esta retirada provocava um abaixamento do nível do lençol freático, compensado pela entrada de água do tanque intermediário com simultânea abertura da válvula da bóia que promovia a saída de água do tanque medidor. Ao tanque medidor foi conectada uma fita métrica que permitia medidas da altura de água consumida, descontada da leitura do dia anterior e convertida em milímetros de evapotranspiração através da Equação 1: 


$$
E T o=(L 2-L 1) \times\left(\frac{D 1}{D 2}\right)^{2}
$$

em que:

ETo - evapotranspiração da cultura de referência, $\mathrm{mm} \mathrm{d}^{-1}$;

D1 - diâmetro do tanque medidor, m;

D2 - diâmetro do lisímetro, m;

$$
E T o_{P M}=\frac{0,408 \Delta(R n-G)+\gamma \frac{900}{\text { Tmed }+273,16} U_{2} *(\text { es }-e a)}{\Delta+\gamma\left(1+0,34 U_{2}\right)}
$$

em que:

ETo - evapotranspiração da cultura de referência, $\mathrm{mm} \mathrm{d}^{-1}$;

$\Delta$ - declividade da curva de pressão de vapor de saturação, $\mathrm{KPa}^{\circ} \mathrm{C}^{-1}$;

$\lambda$ - calor latente de evaporação, $\mathrm{MJ} \mathrm{kg}^{-1}$;

rc - resistência do dossel da planta $\mathrm{s} \mathrm{m}^{-1}$;

ra - resistência aerodinâmica, $\mathrm{s} \mathrm{m}^{-1}$;

$\mathrm{Rn}$ - saldo de radiação à superfície, $\mathrm{KJ} \mathrm{m}^{-2} \mathrm{~s}^{-1}$;

$\mathrm{G}$ - fluxo de calor no solo, $\mathrm{KJ} \mathrm{m}^{-2} \mathrm{~s}^{-1}$;

$\gamma$ - constante psicrométrica, $\mathrm{KPa}{ }^{\circ} \mathrm{C}^{-1}$;

$\mathrm{T}$ - temperatura média do ar, ${ }^{\circ} \mathrm{C}^{-1}$;

$\mathrm{U} 2$ - velocidade do vento a $2 \mathrm{~m}$ de altura, $\mathrm{m} \mathrm{s}^{-}$ 1 ;

DPV - déficit de pressão de vapor, KPa; e
L1 - leitura do dia, mm;

L2 - leitura do dia anterior, mm;

Determinação da evapotranspiração de referência (ETo) por meio dos dados da estação agrometeorológica

O modelo de Penman-Monteith (Allen et al. 1998), pode ser descrito como: 
Para cálculo da ETo, foram usadas as leituras provenientes do lisímetro padrãograma e da equação de Penman-Monteith FAO-56 (Allen et al. 1998) descritos na Tabela 1. O maior valor de ETo determinado $\left(5,6 \mathrm{~mm} \mathrm{~d}^{-1}\right)$ ocorreu no dia 27 de fevereiro e foi superior aos demais observados. $\mathrm{Na}$ Tabela 1, é possível observar que, nesse dia 27, a umidade relativa média estava abaixo de $70 \%$ (valor abaixo da média normal para o mês de março na região), e a velocidade do vento foi à máxima observada no período $(\approx$ $\left.0,7 \mathrm{~m} \mathrm{~s}^{-1}\right)$. O maior valor de ETo estimado $\left(6,2 \mathrm{~mm} \mathrm{~d}^{-1}\right)$ ocorreu no dia 01 de março e foi superior aos demais observados. Na Tabela 1 , é possível observar que, nesse dia 01, a umidade relativa $73,8 \%$, e a velocidade do vento foi média observada no período $(\approx 0,7$ $\left.\mathrm{m} \mathrm{s}^{-1}\right)$. A variação dos valores dos elementos climáticos apresentados refletiu na análise de correlação entre os dados de ETo.

Na Figura 4, apresenta-se a dispersão obtida entre os valores medidos e estimados de ETo. A análise de correlação mostra coeficiente de determinação de 0,51, semelhante aos obtidos por Medeiros et al. (2003), trabalhando em Paraipaba - CE $\left(r^{2}=\right.$ $0,56)$, e por Mendonça et al. (2003), para o Norte-Fluminense $\left(r^{2}=0,58\right)$. Descartando alguns valores discrepantes medidos pelo lisímetro, em razão de chuvas e rajadas de vento no período, o coeficiente de determinação obtido evidenciou ajuste satisfatório entre as medidas lisimétricas e os valores obtidos pelo modelo de PenmanMonteith, padronizado pela FAO (Silva et al. 1999; Mendonça et al. 2003).

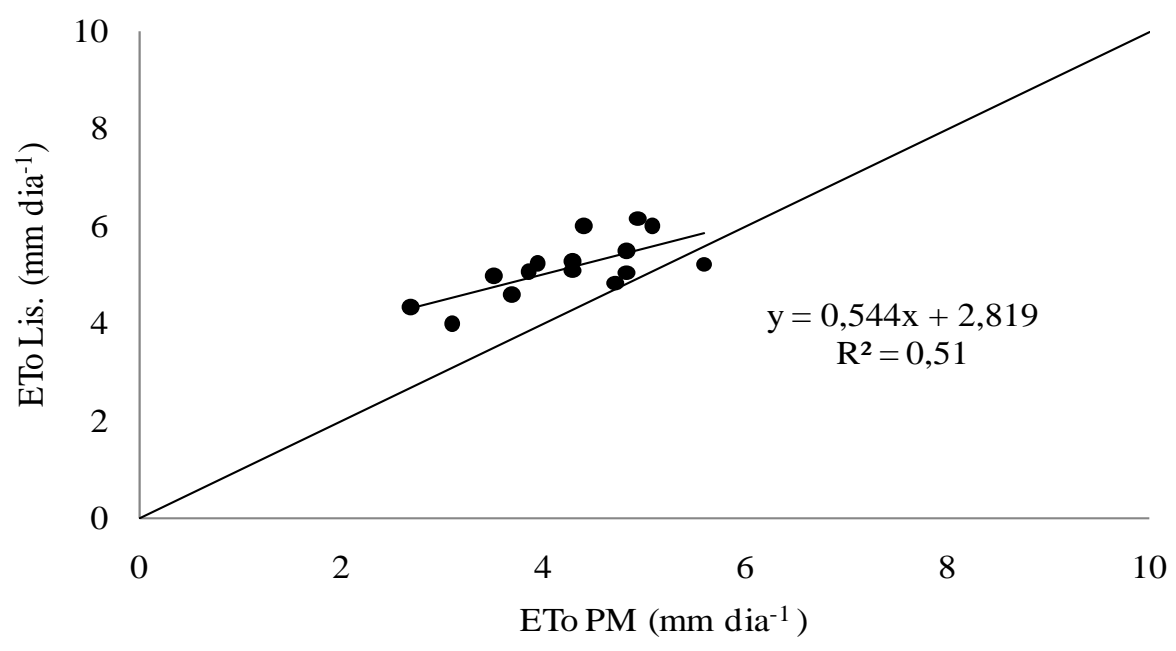

Figura 4. Correlação entre os valores diários da evapotranspiração de referência $\left(\mathrm{mm} \mathrm{d}^{-1}\right)$ medidos pelo lisímetro (ETo Lis.) e estimados por Penmam-Monteith (ETo PM).

Assim, ressalta-se que, mesmo com pequeno período de dados analisados e com a ocorrência de chuva no período, os valores de ETo obtidos no lisímetro se mostraram bem correlacionados com aqueles estimados pelo modelo. Apesar desta avaliação, é importante salientar a necessidade de análise contínua dos dados obtidos no lisímetro com os elementos meteorológicos que interferem no processo evapotranspirativo, para que o manejo da irrigação seja efetuado de maneira satisfatória.

\section{CONCLUSÕES}

O lisímetro construído foi instalado e calibrado adequadamente, apresentando boas 
condições de funcionamento e permitindo a obtenção de medidas de evapotranspiração em concordância com estimativas realizadas pelo método de Penman-Monteith, na região de Mutuca - PE.

\section{REFERÊNCIAS BIBLIOGRÁFICAS}

ALLEN, R.G.; PEREIRA, L.S.; RAES, D.; SMITH, M. Crop evapotranspiration: guidelines for computing crop water requirements. Rome: FAO, 1998. 301p. (FAO Irrigation and Drainage, Paper 56).

FARIA, R.T. de.; CAMPECHE, L.F.S.M.; CHIBANA, E.Y. Construção e calibração de lisímetros de alta precisão. Revista Brasileira de Engenharia Agrícola e Ambiental, v.10, n.1, p.237-242, 2006.

KASHYAP, P.S.; PANDA, R.K. Evaluation of evapotranspiration estimation methods and development of crop-coefficients for potato crop in a sub-humid region. Agricultural Water Management, Amsterdan, v.50, n.1. p.9-25, 2001.

MACHADO, R. E. E.; MATTOS, A. Construção e instalação de um lisímetro com sistema de drenagem. Revista Brasileira de Agrometeorologia, v. 9, n. 1, p. 147-151, 2001.

MEDEIROS, A. T.; SENTELHAS, P. C.; LIMA, R. N. Estimativa da evapotranspiração de referência a partir da equação de Penman-Monteith, de medidas lisimétricas e de equações empíricas, em Paraipaba - CE. Engenharia Agrícola, v.23, n.1, p.21-30, 2003.

MENDONÇA, J.C.; SOUZA, E.F.; BERNARDO, S.; DIAS, G.P.; GRIPPA, S. Comparação entre métodos de estimativa da evapotranspiração de referência (ETo), na região Norte Fluminense - RJ. Revista Brasileira de Engenharia Agrícola e Ambiental, v.7, n.2, p.275-9, 2003.

MOURA, M. T. V. et al. Estimativa do consumo de água na cultura da cenoura (Daucus carota L.) v. Nantes Superior, para a região de Piracicaba, através do método do balanço hídrico. Scientia Agrícola, v. 51, n. 2, p.284-291, 1994.

MOLINIER, M.; ALBUQUERQUE, C.H.C. \& CARDIER, E. Análise de pluviometria e isoietas homogeneizadas do nordeste brasileiro. Recife, Sudene 58p. (Hidrologia, 32), 1994.

SANTOS, F.X. dos.; RODRIGUES, J.J.V.; MONTENEGRO, A.A.A.; MOURA, R.F. de. Desempenho de lisímetro de pesagem hidráulica de baixo custo no semiárido nordestino. Engenharia Agrícola, v.28, n.1, p.115-124, 2008.

SILVA, F.C.; FOLEGATTI, M.V.; PEREIRA, A.R.; VILLA NOVA, N.A. Uso de dispositivos lisimétricos para medida da evapotranspiração de referência. Revista Brasileira de Agrometeorologia, v.7, n.1, p.19-23, 1999.

VELLAME, L.M.; COELHO FILHO, M. A.; COELHO, E.F.; FRAGA JÚNIOR, E. F. Lisímetro de pesagem e de lençol freático de nível constante para uso em ambiente protegido. Revista Caatinga, Mossoró, v. 25, n. 1, p. 153-159, 2012. 
Santos et al.

TABELA 1. Valores de evapotranspiração de referência medidos em intervalos de dois dias (ETo Lis.) e estimados (ETo PM), radiação solar incidente (Rs), umidade relativa (Ur), temperatura média (T), velocidade do vento (Vv) e precipitação (P), no período de 25-02-2015 a 25-03-2015.

\begin{tabular}{cccccccc}
\hline Data & ETo Lis & ETo PM & Rs & T & Ur & Vv & Ppt \\
\hline $25 / \mathrm{fev}$ & 4,8 & 5,1 & 22,5 & 24,6 & 70,5 & 1,2 & 0 \\
$27 / \mathrm{mar}$ & 5,6 & 5,2 & 26,8 & 24,8 & 67,3 & 0,7 & 0 \\
$01 / \mathrm{mar}$ & 5,0 & 6,2 & 19,5 & 24,6 & 73,8 & 0,7 & 20 \\
$03 / \mathrm{mar}$ & 3,9 & 5,2 & 21,6 & 24,0 & 68,2 & 1,3 & 0 \\
$05 / \mathrm{mar}$ & 4,3 & 5,1 & 21,5 & 23,8 & 78,9 & 1,3 & 0 \\
$07 / \mathrm{mar}$ & 3,1 & 4,0 & 26,3 & 24,3 & 68,8 & 1,0 & 0 \\
$09 / \mathrm{mar}$ & 4,7 & 4,8 & 12,2 & 23,9 & 80,8 & 0,7 & 0 \\
$11 / \mathrm{mar}$ & 3,8 & 5,0 & 26,1 & 24,8 & 67,3 & 1,2 & 0 \\
$13 / \mathrm{mar}$ & 4,4 & 6,0 & 23,9 & 24,8 & 69,6 & 1,4 & 0 \\
$15 / \mathrm{mar}$ & 5,1 & 6,0 & 19,9 & 24,8 & 68,7 & 1,1 & 0 \\
$17 / \mathrm{mar}$ & 4,8 & 5,4 & 21,6 & 24,7 & 69,9 & 1,1 & 0 \\
$19 / \mathrm{mar}$ & 4,3 & 5,2 & 21,2 & 24,0 & 70,4 & 1,5 & 0 \\
$21 / \mathrm{mar}$ & 3,7 & 4,6 & 19,3 & 25,1 & 71,8 & 0,8 & 0 \\
$23 / \mathrm{mar}$ & 2,7 & 4,3 & 23,8 & 23,2 & 82,4 & 0,7 & 14,4 \\
$25 / \mathrm{mar}$ & 3,5 & 4,9 & 24,4 & 25,4 & 70,4 & 1,2 & 0 \\
\hline
\end{tabular}

